Marta Tymińska

University of Gdansk

\title{
Avatars Going Mainstream: Typology of Tropes in Avatar-Based Storytelling Practices
}

\section{Introduction}

Being trapped in a computer game, fighting evil Artificial Intelligence, saving the world or at least virtual reality - those tropes are common in contemporary novels, comic books and motion pictures. The majority of popular, mainstream culture recognizes digital games, virtual reality and the Internet as part of everyday experience, therefore it often incorporates them in its narratives. The influence of games upon other media transpires in various forms: from including such themes in world-building and storytelling to creating spaces imitating game-like experiences. Avatars started to appear in various titles as main characters or projections thereof. The inclusion of avatars in such non-game narratives can recreate the common knowledge of digital game context or various misconceptions that authors of other popular media hold regarding player-avatar phenomena.

The aim of this article is to investigate popular tropes within avatar-based storytelling practices present in popular media other than digital games. Inspired by Ted Friedman's work (2005) on cybercultures and representation of computers in popular culture, this paper will focus on avatar-related tropes through an analysis of a range of texts such as: comic books, motion pictures, animations, TV series, and whole franchises. The results will be confronted with the most recent research in the matter of avatars in game studies.

This approach will enable me to create a typology of narrative tropes connected with the gaming experience throughout the avatars and to explore the avatar- 
-player relationship. Confronting those tropes with the digital game research might unravel the hopes and expectations as well as doubts and fears that are connected with gaming experience within the globally understood popular culture. The main thesis of this text is that avatar-based narratives are creating an idealistic and often misleading vision of human-avatar interactions, which consists of deep immersion, identity transfer, and strong emotional connection with the game environment.

\section{Avatar studies perspective}

Avatar studies, which examine player representation in digital games, are growing more popular as part of game studies in general. The emphasis is placed on various topics: player-avatar relationship (Banks \& Bowman, 2014; Taylor, 2002), player-avatar behavior (Fox et al., 2014), and psychological processes (Banks \& Bowman, 2014; Yee, 2006; Yee \& Bailenson, 2007) that take place within virtual environment. One of the most known pieces of research on avatars is Rune Klevjer's (2006) dissertation where he distinguishes avatar-based single-player games from other video game genres. The term "avatar" also became widely popular among gamers, who consider it as a natural part of their gaming experience (Banks \& Bowman, 2014). Some scholars tend to distinguish between avatars and playable characters, based mostly on the agency provided by developers as well as possibilities of character customization (Willumsen, 2016). Digital game avatars are recognizable phenomena with which most of popular culture consumers, defining themselves as geeks or nerds, are familiar. Avatar use in games has aesthetic consequence, as well as influence on one's gaming experience (see Klevjer, 2006). Therefore, there is a growing need to define and describe digital games avatars in their diversity. The interest of researchers rarely leans toward re-interpretation of digital games within other narrative media, with the exception of analyzing the influence of video games on their aesthetics (Girina, 2015) and their narrative aspects (Katsaridou, 2014).

Throughout this paper, the term "avatar" will refer to any visual (and sometimes audial) representation of a player within the digital game environment. The term "digital" implies all the gaming experience that is mediated with electronic devices processing digital data, such as personal computers, smartphones, or gaming consoles. "Playable character" or "game character" might be used interchangeably as it is important to broaden the definition and include more of popular culture texts. The social media context will not be analysed as it requires a broader theoretical framework. 


\section{Avatar-based storytelling practices}

The transfer of human consciousness into cyberspace by means of attaching one's body to a computer or similar device was always a motif that fascinated science fiction and cyberpunk writers, with the most prominent examples of William Gibson's Count Zero (1983) and Neal Stephenson's Snow Crash (1993). The term “avatar” itself originated from the Sanskrit word for a deity embodied on Earth - avatāra (अवतार) - and it is still traditionally used as such (Ahn et al., 2012). Since the term was introduced into the game industry discourse by titles such as Ultima IV: Quest for the Avatar (Origin Systems, 1985) and Habitat (Lucasfilm Games, 1986), it gained popularity and finally settled as an official term for creating, personalizing, or inhabiting a particular character in games (Ahn et al., 2012).

Literature was not the only area that started very early to tackle the issues of in-game presence. Disney's sci-fi motion picture Tron (1982) might be described as one of the first, if not the first movie that presented the perspective of human players captured inside a game, interacting not only with other game characters but also computer software. A different idea of entrapment in a game was presented 17 years later in David Cronenberg's eXistenZ (1999), which mostly focused on the dangers of illusions created by video games and their addicted users. The year 1999 also witnessed Wachowskis' Matrix (1999) premiere, another significant step on the way to presenting and understanding the cinematic take on virtual reality and transfer of consciousness. Despite its incredible success as transmedial cultural phenomenon, Matrix focuses on the idea of virtual reality and does not include a gaming experience in its narrative. A similar perspective of dealing with digital representations is to be found in the Japanese animated series Serial Experiments Lain (1998), which primarily describes the problem of virtual reality and online existence but does not involve a game-related experience.

The construct of avatar might be understood as two different ideas. One that is coherent with its user's identity might be found on discussion forums or in social media. The other that encourages building the persona with creativity is more common for video games. As Sercan Sengün (2015) states: "[a]s opposed to other virtual spaces that invite their users to create avatars that could represent (thus bear a likeness of) them or in cases such as Facebook and Google Plus that encourage their users to utilize their real-world identities; video game spaces steer them to create (or take control of) fictional avatars that could orient them in fictional worlds" (p. 182). Therefore, popular narratives reflect on both of those perspectives as well as reflect them in their plots and world-building, often merging them into one. 
Simultaneously, with the development of the Internet and of various narratives concerning online games became widely popular not only among gamers but also the general public. Since the launch of the first two MMORPGs (massively multiplayer online role-playing games): Meridian 59 (Archetype Interactive, 1996) and Ultima Online (Origin Systems, 1997), the social dimension of playing videogames has become more global and universal as an experience of a generation. The introduction of Second Life (Linden Research Inc., 2003) sparked interest among mainstream media, researchers and scholars worldwide (Kolo \& Baur, 2004; Boellstorff, 2012; Banks \& Bowman, 2014), resulting in more in-depth studies of avatar-player interaction (Banks \& Bowman, 2014) and avatar cultures (Taylor, 2002; Boellstorff, 2012). Between 1996 and 2010 there was a significant growth in the bulk of TV series, books, as well as documentaries that started to include avatar-themed narratives, which can be considered a beginning of a new subgenre in between science-fiction, fantasy and adventure stories.

One of the earliest series that portrayed the human-avatar relationship was the Digimon franchise and its TV series (1999), which started as a game and then was turned into an animation that explored the topic of a world mediated through virtual environment. It also featured children transferred into the digital world, where they functioned as their own avatars. This was neither the first nor the most revolutionary title; however, it became widely popular mostly because of its audience targeting. Children and pre-teens could easily relate to the experience of exploring fantastic worlds through electronic devices.

Out of various interesting titles, those aimed at children, teenagers, and young adults explore avatars and the gaming experience in the most creative way. At the same time, works addressed to adults are either nostalgic about the gaming experience or emphatic about the fear of modern technologies. However, most of these narratives are similar to each other, use similar tropes and reproduce similar misconceptions regarding player-avatar phenomena.

\section{The notion of trope in popular culture narratives}

As English Oxford Living Dictionaries states, a trope is "a figurative or metaphorical use of a word or expression", which is followed by supplemental definition as it is also a significant or recurrent theme; a motif" ("Trope", n. d.). While considering tropes in popular culture, a much broader perspective must be taken into consideration.

In literary theory, trope is considered "something that can be named in no literal way" (Miller, 1990, xi), which means that in various texts it adopts different form and 
rhetoric. Its more modern understanding dates back to Umberto Eco's essays and it was easily adopted by fan-academics as something instantly recognisable by viewers and readers but not explicitly said or done within the textual layer (Börzsei, 2015).

The idea of following popular motifs (defined and known as "tropes") was popularized by the fan-driven Wiki page named "TV Tropes". The whole process of a trope becoming a part of cyberculture was described thoroughly by Emily Brehob (2013) and Linda Kata Börzsei (2012). Tropes are understood as "devices and conventions that a writer can reasonably rely on as being present in the audience members' minds and expectations" (see Brehob, 2013), which means that there is a similar understanding of events, aesthetics, characteristics among a wide group of viewers, listeners, and readers. Simultaneously, those are part of both digital culture and literary theory, creating bridge between new and traditional media narratives. Therefore, avatar-based narratives contain a variety of tropes which might be seen as a glimpse of globalized experience of play. Still, they also reproduce many misconceptions about playing games as well as the players' motivations. There are several important tropes that are prevalent among various works, however, some of them occur more often than others as they appear to be more familiar to the audience. Surprisingly, sometimes even opposite tropes might work within one narrative, which might deepen the misconceptions about the player-avatar relationship. Unfortunately, authors and screenwriters often do not understand the phenomena of gameplay, which results in lack of its proper representation. Avatar-based storytelling practices do not use the proper terminology, however, they tend to express the gaming experience and refer to the phenomena of digital games.

Distinguishing between a game and non-game narratives might be crucial for understanding the presence of avatars in media other than digital games. As mentioned before, there are titles that tackle the issue of virtual reality and are often inspired by digital games. They might fail in expressing the gaming context, they nevertheless convey some general knowledge on avatar-player relationship, and therefore they will be included in the analysis as avatar-based narratives. The reason for focusing on such particular thematic genre in other media is mostly the fact that there is a growing number of narratives that draw from gaming experience. The use of avatars as main characters or part of the story emphasizes the importance of digital games in modern culture and projects general predictions about the future of gaming and technology.

The term "avatar" does not have to be used in these stories in direct manner for it to be included in this analysis. Therefore, a given work has to have a recurring - not episodic - motif of in-game presence. It also has to frame human-avatar and human- 
-computer interactions within the story. James Cameron's Avatar (2009), as well as Avatar - The Last Airbender (2005), cannot be considered part of the discourse, as those movies employ the term in reference to the traditional deity-on-Earth understanding of this word. Further examples of movies and novels that are excluded from this analysis are titles that are directly based on video games and are recreating the basic storyline, such as Lara Croft: Tomb Raider (2001) or Mortal Kombat (1995). These adaptations of game titles do not recognize them as avatars, but as fully independent characters with their own stories to present. Such titles do not portray the specific character of player-avatar interactions. The only exception is Wreck-it-Ralph (2012), being a unique reflection on the non-playable and playable characters in their relation to ever changing gaming culture.

\section{Selection of avatar-based storytelling practices for this study}

This analysis is based on a close reading of a selected body of material. The criteria for the selection of material were: presence on fan-driven websites, being recognized and recommended by the focus group, and availability in both English and Polish language. The search for the titles started with an analysis of fan-driven sites, such as MyAnimeList.net, TVTropes.org and different wikia projects through their in-site search engines using the terms "video game", "role-playing game" and "trapped in video game". At that stage, the number of texts was narrowed to 42 . With the biggest representation coming from Japan and United States, it also includes titles from South Korea, Russia, and France. The research was then supplemented with fan driven folksonomy (Johnson, 2014). The list of the titles was confronted with six competent judges, who were representing gamers, game studies scholars and members of multiple fandoms, known as "multifandom" (Johnson, 2014). The final number of texts is 14. The list is not complete, yet it consists of titles available both for English and Polish speaking users, which was determined by appealing to the linguistic expertise of the researcher conducting this study.

\section{Typology of avatar tropes}

There are a variety of different tropes and motifs that recur in various novels, films, and television series. This section presents the most popular nine tropes divided into three types that focus on different aspects of avatar existence within the texts presented in Table 1. 


\begin{tabular}{|l|l|}
\hline Type of trope & Name of the trope \\
\hline Avatar transparency tropes & behavioral realism \\
\cline { 2 - 2 } & isomorphism \\
\hline \multirow{3}{*}{ Human-avatar contrasts tropes } & idealisation \\
\cline { 2 - 2 } & escapism \\
\hline \multirow{3}{*}{ Understanding avatars in games tropes } & magic circle \\
\cline { 2 - 2 } & permadeath \\
\cline { 2 - 2 } & no-NPCs \\
\cline { 2 - 2 } & the evil Al \\
\hline
\end{tabular}

Table 1. Typology of Tropes in Avatar-Based Storytelling Practices

\section{Avatar transparency tropes}

The first type of trope deals with the player-avatar relationship and the transparency of the latter. The player in those stories creates a unit with a virtual representation and does not differentiate between the "self" and the in-game character.

According to personal trope analysis, one of the most conventional ones to be found in avatar-storytelling is "behavioral realism" (Ahn et al., 2012), which can be defined as a complete compatibility between the player and the avatar. A good example is Tsukasa, the protagonist in the Japanese animated series .hack//SIGN (2002), widely popular among global manga and anime fandom. The character declares perfect consistency between how he would behave in the real world, which means mostly shying away, and admits that the game makes him a better person. A similar relationship is observable with regard to characters from the French animation titled Code Lyoko (2003). Although the protagonists do not enter a digital game but rather a virtual environment, their avatars seem to be direct transfers of their consciousness. All the virtual characters behave just like their human users. In this narrative frame, the player has full control over the avatar and does not differentiate between reality and the game. Jamie Banks and Nicholas D. Bowman (2013) describe such attitude as one of four different modes of player-avatar relationship that were established within the Player-Avatar Relationship Scale. According to this research, players who "integrate play and everyday life into cohesive social reality and see avatars as themselves (rather than as a separate entity) across both spaces" (Banks \& Bowman, 2013) are put into the "avatar-as-me" category. There are three more relationship descriptions provided by Banks and Bowman (2013): "avatar-as-object", "avatar-as-symbiote" and "avatar-as-other". One might think that using various behavioral and human-avatar relationship patterns would make narratives more interesting and complex. However, the screenw- 
riters and creators of those stories choose less sophisticated narrative which is more understandable for the audience. Thus, they provide clear and precise storytelling which otherwise might be too difficult to comprehend.

Another intriguing trope relating to the previous two is "isomorphism" (Boellstorff, 2011), which can be characterized as creating an avatar that resembles the player visually. This might be noticeable in the mentioned above Digimon franchise (1999), Code Lyoko (2003) and Sword Art Online (Kawahara, 2014), as well as the American web series The Guild (2007), where MMO characters are played by actors and resemblance is inevitable. This is also often the case of portraying a beginner player, who explores digital games for the first time and finds it obvious that the avatar should resemble him - or herself. This attitude is noticeable in a Danish documentary Min Avatar Og Mig (2011) - the protagonist decides to explore Second Life (2003) and presents his relationship with his avatar and the game. Boellstorff $(2011 ; 2012)$ implies that it common practice among gamers to create similar and adequate avatars in Second Life but also proves that it can be transgressed. However, the case of isomorphism might be comparable only for minority of white players of MMORPGs, where their avatar might be compared to others and judged by its looks. Lisa Nakamura $(2002 ; 2015)$ states that players and Internet users that identify themselves as people of color would rather hide their ethnic identity, and tend to disguise as white majority. Avatars in TV series and movies bear very strong resemblance to their owners and creators, as it enables the viewers to connect each character with their virtual counterpart. This seems to be the best explanation of this trope's existence.

\section{Human-avatar contrast tropes}

The second type of tropes represents a tendency to present avatars as a means to escape everyday life and create stories better and more satisfying than "real life" stories. Such representations exploit mostly two motives: the tendency to idealise in-game avatars and the "escape" from the difficulties of out-of-game life.

The first one is the idealisation trope (sometimes contrasted with behavioral realism), which is connected with a human tendency to create better or completely opposite versions of ourselves. This situation is ridiculed by one of the characters in the Polish feature film Suicide Room (2010). A group of misfits briefly portrayed in this movie finds their peace in a Second Life-resembling game. It lasts until one of them discovers their "real-life" identities and decides to reveal their imperfections to the others. A similar mechanism is visible in Sword Art Online - a series of Japanese novels by Reki Kawahara (2014) - where players trapped in virtual reality MMORPG are 
forced to adapt their avatars' looks to the way they look in real life, which proves that almost all players tend to create more satisfying versions of themselves. Nick Yee and Jeremy Bailenson (2007) claim that "idealisation" in digital game environment might influence the outside-of-the-game, actual behavior. These researchers propose the existence of the "Proteus Effect", which suggests that people who were rendered taller or more attractive than in reality behaved differently both in the game context as well as in actual interactions with others (Yee \& Bailenson, 2007).

Various protagonists from avatar-based narratives tend to explain their motivation of playing (or being captured inside the game) with the escapism trope. Kirito from Sword Art Online (Kawahara, 2014), Tsukasa from .hack//SIGN , as well as Dominik and Sylwia from Suicide Room (2011) find the ability to escape into the virtual world more attractive and interesting than real life. The message hidden within this trope presents an unfavorable and negative approach towards this "escapist" behaviour. It is also one of the most common stereotypes about players - due to their inability to function properly, they tend to find refuge in digital games (Calleja, 2010). Gordon Calleja (2010), however, demonstrates that the notion of escapism should be reevaluated and considered a useful device in terms of shaping behavior in actual life.

\section{Understanding avatars in games tropes}

The third trope group corresponds with in-game mechanics that are more or less a realistic representation of gameplay and human-avatar relationships (and understanding thereof). They are less common, more varied, and usually are not shared between all works with the exception of the magic circle trope.

As the (quite controversial) division between the "virtual" and the "actual" (Boellstorff, 2011, p. 505) goes, ${ }^{1}$ there is another stereotype that conveys the narrative of an opposite, separate world, connected only by a virtual platform. The magic circle trope is quite prevalent and vivid, especially in more epic, role-playing game inspired narratives. The idea itself was introduced by Johan Huizinga in Homo ludens (1949), where it is compared to: "the arena, the card table, the magic circle, the temple, the stage, the screen, the tennis court, the court of justice, etc." (p. 10). Consalvo refers to it as that place, where "different rules apply, and it is a space where we can experience things not normally sanctioned or allowed in regular space or life" (2009, p. 409), and then criticizes it strongly. Consalvo states that the belief in the existence of a "magic circle" while playing digi-

1 The decision to divide the gaming experience and out-of-game reality to "virtual" and "actual" (Boellstorff, 2011) is motivated by the iniquitousness of gaming experience as well as the fact that it resonates with Consalvo's criticism of the notion of magic circle. 
tal games is false, mostly because the effects of in-game interactions and in-game choices might resonate not only with friends but also the whole gaming community (2009). However, many scholars, Jaakko Stenros among them, defended its existence by identifying borders of play (2014), which are consistent with the described trope. He states that the act of play is impossible without establishing borders between the game and the outside world (Stenros, 2014). The magic circle trope illustrates the creators' need to emphasize that both in-game behavior and in-game events remain within the game context. It may be treated as contradictory to behavioral realism; however, in most narratives these tropes exist simultaneously. This can be illustrated briefly by the .hack//SIGN series, where the viewer doesn't know what the characters look like or how they behave outside the game, yet one is informed that characters have similar character traits and behavioral patterns as in the real life. Using the notion of the "magic circle" creates the atmosphere of uniqueness of gaming experience and separates it from everyday life. Some of the titles intentionally play with this trope, while proving that what happens in "virtual" or in "actual" life (Boellstorff, 2011, p. 505) is deeply intertwined and inseparable from each other. The Japanese animated feature film Summer Wars (Hosoda, 2009) portrays a near-future society that uses an integrated gaming and social media platform to integrate a variety of services provided in actual life, such as healthcare or crisis management. Some of the users distinguish strongly between their avatars and their actual selves, however, the whole society suffers when the system is struck down, destroying the illusion of the magic circle. In Japanese light novels, such as Sword Art Online (Kawahara, 2014), OverLord (Maruyama, 2010) or Log Horizon (Touno, Hara, 2015), the magic circle is forced upon players that are somehow trapped by a malevolent Artificial Intelligence or by other, more vicious, players (TV Tropes).

Numerous texts explore a trope inextricably entwined with magic circle issues the problem of "permadeath" (Rousse, 2011). Protagonists trapped in a digital game or environment suffer dire consequences of their transgressions - they might die in their actual life, mostly due to brain damage caused by VR headsets. While permadeath is uncommon in game design and considered a very controversial facet of game mechanics (Rousse, 2011), the popularity of this trope within avatar-based narratives is significantly higher. The risk of death of a favorite character might be used as a plot device and create proper dynamics within the narrative.

Digital games represented in books, movies, and TV series are very often filled with avatars and very rarely with non-playable characters (NPC), therefore the no-NPC's trope is another interesting feature of avatar-based narratives. Leaving aside Wreck-it-Ralph (2012), where all the characters are either sentient, independent avatars or non- 
-playable characters, the vast majority of those narratives do not include non-playable .characters, finding them unnecessary. A significant exception to this rule is to be found in Code Lyoko, where one of the heroines - Aelita - is in fact an NPC who became sentient and escaped the virtual world. This trope actually reflects game studies research that proved a significant difference between human behavior towards an avatar (which represents a human being on the other side) and towards an agent (artificial intelligence programmed to behave in a particular way). Jamie Fox et al. (2014) draw our attention to various attitudes towards agents - other players are often dismissive of them or ignore them and they are less likely to interact with agents (or NPCs) if they are aware of those characters being controlled by a computer program (Fox, et al., 2014).

Sometimes the presence of a non-playable character within the narrative transforms into the evil AI trope. Somehow the malevolent artificial intelligence tries either to rule the virtual world it inhabits or to inhabit and colonize the actual world. Most of those AIs are presented as clichéd main antagonists throughout the series. This is not exclusive to avatar-based narratives, as it is more common in most science fiction narratives ("TV Tropes"). This can be illustrated by the character of Agent Smith from the Matrix franchise (1999) as well as the evil A.I. X.A.N.A. from Code Lyoko series (2003). It seems that using an artificial enemy makes it possible to show fights and violence without shocking the underage fans of the series. NPCs and AIs tend to be very often dehumanized, and when they are destroyed by protagonists it is not counted as "kill" or "death". According to some pieces of research, A.I. can be also perceived as an agent without human features or skills, therefore, it is not treated with sympathy by gamers or software users (Fox et al. 2014).

Finally, there is also a group of non-typical tropes that occur within avatar non-game narratives such as: transferring consciousness, saving the world through video games, time-travel and entrapment. All of those are equally interesting; however, they do not refer closely to the actual gaming experience as well as to the current state of technical advancement. Those motifs are embedded in the game-related narratives, yet do not depend on them exclusively and are mostly used as plot devices or mere episodes. The more in-depth analysis of those might be useful and relevant for further studies of computer technology and the Internet as a part of popular culture (Friedman, 2005; Schulte, 2013).

\section{Conclusion}

The research has uncovered a variety of tropes that are included in avatar-based storytelling practices, franchises, and media projects, which prove that not all gaming experience is presented accordingly, some of the avatar-based narratives include 
stereotypes and misconceptions that are undergoing reevaluation within games studies.

The tropes were divided into three types with regard to different aspects of gaming experience: (1) player-avatar relationship (avatar transparency), (2) game as a means of retreat (human-avatar contrasts), and (3) the uniqueness of gaming experience issues (understanding avatars in games). In the first type we can distinguish: behavioral realism and isomorphism. The second type is also represented by two popular tropes: idealisation and escapism. Finally, the third type puts emphasis on the specific character of gaming as an experience. The tropes described in this part are: magic circle, permadeath, no-NPCs, the evil AI (see also Table 1).

The proposed typology of tropes enables understanding of how popular culture perceives gaming experience and the player's identity. Those tropes evoke a vision of immersive and ubiquitous future of gaming, where the player and avatar are most likely the same being. This might be considered to show both the expectations and concerns regarding the human-avatar relationship.

Still, while this article hints at some of the possible applications of avatar-related tropes in non-game narratives, further research seems to be necessary in order to provide a comprehensive review thereof. Firstly, some valuable information might be revealed through cross-cultural, qualitative and quantitative research on various tropes present in narratives with different gaming cultures. Secondly, information might be gained through exploring more tropes in relation to not only critical framework but also design studies; and thirdly, through creating a database of avatar related tropes not only in avatar-based narratives but also as separate incidents in more mainstream cultural texts, and finally including game-based adaptations.

Definitely there will be more and more non-game narratives tackling the issue of in-game presence and gaming experience as well as exploring human-avatar relationship. This seems to be the case because contemporary culture is undergoing a "geek revolution" (Dennis, 2015), which may result in the appearance of different, more transmedia narratives.

\section{Acknowledgments}

This paper was supported by the knowledge and feedback from CEEGS 2015 participants and Replay Editorial Staff. My special gratitude goes to both of my anonymous reviewers that gave me insight, advice, and all possible help to make this paper valid 
and well-structured. I want also to thank Maria B. Garda for assistance with the editing process that greatly improved the manuscript.

\section{References}

Ahn, S. J., Fox, J., Bailenson, J. N., (2012). Avatars, In W. S. Bainbridge (Ed.), Leadership in Science and Technology: A Reference Hanbook, Volume 2 (695-702). London, UK: SAGE Reference

AI Is A Crapshoot. (n.d.). Retrieved November 25, 2016 from the TV Tropes Wiki: http://tvtropes.org/pmwiki/pmwiki.php/Main/AIIsACrapshoot

Bailenson, J. N., Blascovich, J. Avatars [PDF document]. Retrieved from Virtual Human Interaction Lab from Stanford University: https://vhil.stanford.edu/ $\mathrm{mm} / 2004 /$ bailenson-avatars.pdf

Banks, J., Bowman, N. D. (2013). Close intimate playthings? Understanding player-avatar relationships as a function of attachment, agency, and intimacy. Retrieved from Academia.edu: https://www.academia.edu/3712635/Close_intimate_playthings_Understanding_player-avatar_relationships_as_a_function_of_attachment_agency_and_intimacy

Banks, J., Bowman, N. D. (2014). Avatars are (sometimes) people too: Linguistic indicators of parasocial and social ties in player-avatar relationships. New Media \& Society, [online ahead of print]. doi: 10.1177/1461444814554898

Boellstorff, T. (2011). Virtuality. Placing the Virtual Body: Avatar, Chora, Cypherg... In. F. E. Mascia-Lees (Ed.), A Companion to the Anthropology of the Body and Embodiment, Chichester, West Sussex, U.K.; Malden, MA: Wiley-Blackwell, 2011.

Boellstorff, T. (2012). Dojrzewanie w Second Life. (A. Sadza, Trans.). Kraków: Wydawnictwo Uniwersytetu Jagiellońskiego. (Original work published 2008).

Börzsei, L. K. (2012). Literary Criticism in New Media. A critical analysis of the website Television Tropes and Idioms and the place of literature in digital culture. Retrieved from Academia.edu.

Brehob, E. (2013). The Wiki TV Tropes as a Community of Pseudo-Academic Producers. Retrieved from Deep Blue: https://deepblue.lib.umich.edu/handle/2027.42/98865.

Brehob, E. (2013). The Wiki TV Tropes as a Community of Pseudo-Academic Producers. Retrieved from Deep Blue University of Michigan Database: https://deepblue.lib. umich.edu/handle/2027.42/98865

Calleja, G. (2010). Digital Games and Escapism. Games and Culture, 4(5), 335-353 [online ahead of print]. doi: 10.1177/1555412009360412 
Consalvo, M. (2009). There is No Magic Circle. Games and Culture, 4(4), 408-417. DOI: $10.1177 / 1555412009343575$

Cyberspace. (n.d.) Retrieved November 25, 2016 from the TV Tropes Wiki: http:// tvtropes.org/pmwiki/pmwiki.php/Main/Cyberspace

Deep Immersion Gaming. (n.d.). Retrieved November 25, 2016 from the TV Tropes Wiki: http://tvtropes.org/pmwiki/pmwiki.php/Main/DeepImmersionGaming

Dennis, C., (2015). How Geek Culture Is Changing The World For Better. Retrieved from http://moviepilot.com/posts/2681242

Fox, J., Ahn, S. J., Janssen, J. H., Yeyekis, L., Segovia, K. Y., Bailenson, J. N. (2014), Meta-analysis: Avatars vs. Agents [PDF document]. Retrieved from Virtual Human Interaction Lab from Stanford University: https://vhil.stanford.edu/mm/2014/foxagents-vs-avatars.pdf

Friedman, T. (2005). Electric Dreams. Computers in American Culture. New York and London: New York University Press.

Gibson, W. (2015). Trylogia ciagu: Neuromancer, Graf Zero, Mona Liza Turbo. (P. W. Cholewa, Trans.). Warszawa: Wydawnictwo Mag. (Original works published 1984,m 1986, 1988).

Girina, I. (2015) Cinematic games : the aesthetic influence of cinema on video games. $\mathrm{PhD}$ thesis, University of Warwick

Hills Miller, J. (1990). Tropes, Parables and Performatives. Durham: Duke University Press

Huizinga, J. (1949). Homo Ludens. A Study of the Play-element in Culture. London, Boston and Henley: Routlege \& Kegan Paul. (Original work published in 1944).

Inside A Computer System. (n.d.). Retrieved November 25, 2016 from the TV Tropes Wiki: http://tvtropes.org/pmwiki/pmwiki.php/Main/InsideAComputerSystem Johnson, S. (2014). Fan Fiction Metadata Creation and Utilization within Fan Fiction Archives: Three Primary Models. Transformative Works and Cultures, 17(1). DOI: http://dx.doi.org/10.3983/twc.2014.0578.

Kamiya, Y. (2016). No Game. No Life. \#1. (M. Sałatkiewicz, Trans.). Warszawa: Waneko. (Original work published 2012).

Klevjer, R. (2006). What is the Avatar? Fiction and Embodiment in Avatar-Based Singleplayer Computer Games. University of Bergen, Bergen.

Katsaridou, M. (2014). Adaptation of Video Games Into Films: The Adventure of the Narrative. Proceedings of The World Congress of the IASS/AIS. Retrieved from: http://iass-ais.org/proceedings2014/view_lesson.php?id=170 
Kawahara, R. (2014). Sword Art Online - Aincrad \#1. (A. Piechowiak, Trans.). Gołuski: Kotori. (Original work published 2009).

Kolo, C., Baur, T. (2004). Living a Virtual Life: Social Dynamics of Online Gaming, 4 (1). Retrieved from http://www.gamestudies.org/0401/kolo/

Kromand, D. (2007) Avatar Categorization. Situated Play, Proceedings of DiGRA 2007 Conference. Retrieved from: http://www.digra.org/wp-content/uploads/digitallibrary/07311.16435.pdf

Manning, P. (2013). Altaholics Anonymous: On the Pathological Proliferation of Parasites in Massively Multiple Online Worlds. Semiotic Review (1). Retrieved from https://www.semioticreview.com/ojs/index.php/sr/article/view/30.

Maruyama, K. (2016). Overlord 1: Nieumarły król. (A. Piechowiak, Trans.). Gołuski: Kotori. (Original work published 2012).

Nakamura, L. (2002) Cybertypes. Race, Ethnicity and Identity on the Internet. London, New York: Routledge.

Nakamura, L. (2015). Racism, Sexism, and Gaming's Cruel Optimism. Retrieved from: https://lnakamur.files.wordpress.com/2015/02/racism-sexism-and-gamings-cruel-optimism.pdf

Rousse, T. (2011). On Permadeath. Retrieved from https://papers.ssrn.com/sol3/papers.cfm?abstract_id $=2001550$

Schulte, S. R. (2013). Cached. Decoding the Internet in Global Popular Culture. New York: NYU Press

Sengün, S. (2015). Why do I fall for the elf, when i am no orc myself? The implications of virtual avatars in digital communıcatıon. Comunicação e Sociedade, 27, 181-193.

Stenros, J. (2014). In Defence of a 'Magic Circle': Transactions of the Digital Games Research Association. Special Issue: Selected articles from Nordic DIGRA, 2 (1). Retrieved from: http://todigra.org/index.php/todigra/issue/view/2

Stephenson, N. (1992). Snow Crash. New York, NY: Bantam Books

Taylor, T. L. (2002). Living Digitally: Embodiment in Virtual Worlds. In R. Schroeder (Ed.), The Social Life of Avatars: Presence and Interaction in Shared Virtual Environments (40-62). London: Springer-Verlag, 2002.

Touno, M., Hara, K. (2016). Log Horizon \#1. (P. Tuczapska, Trans.). Warszawa: Studio JG. (Original work published 2011).

Trope (n. d.) Retrieved Febuary 28, 2017 from English Oxford Living Dictionary: https://en.oxforddictionaries.com/definition/trope

Warpefelt, H., Johansson, M., Verhagen, H. (2014). Analyzing the Believability of Game Character Behavior Using the Game Agent Matrix. DiGRA '13 - Proceedings of 
the DiGra International Conference: DeFragging game studies (7). Retrieved from: http://www.digra.org/digital-library/publications/analyzing-the-believability-ofgame-character-behavior-using-the-game-agent-matrix/

Williumsen E. (2016). Avatar Control and Character Complexity: Defining and Typologizing Character Autonomy. IT University of Copenhagen, Copenhagen.

Yee N., Bailenson, J. (2007). The Proteus Effect of Transformed Self-Representation on Behavior. Human Communication Research, 33, 271-290.

Yee, N. (2006). Project. Retrieved from http://www.nickyee.com/daedalus/.

\section{Ludography}

Archetype Interactive (1996). Meridian 59 [PC Computer, Online Game]. Retrieved from: http://www.meridian59.com/

Linden Research, Inc. (2003). Second Life [PC Computer, Online Game]. Linden Research, Inc: played 25 October 2016

Lucasfilm Games (1986). Habitat [PC]. USA: Museum of Art and Digital Entertainment.

Origin Systems (1985). Ultima IV: Quest for the Avatar [PC]. Poland: GOG.com.

Origin Systems (1997). Ultima Online [PC Computer, Online Game]. Poland: Electronic Arts.

\section{Filmography}

Antefilm/Moonscoop (Producer). (2003). Code Lyoko [Television series]. Paris, France: France 3, Canal J

Bee Train (Producer). (2002). . hack//SIGN [Television series]. Tokyo, Japan: TV Tokyo Cameron J. (Producer), \& Cameron J. (Director). (2009). Avatar [Motion picture]. United States: $20^{\text {th }}$ Century Fox

Cronenberg D., Hamori A., Lantos, R. (Producer), \& Cronenberg D. (Director). (1999). eXistenZ. Canada, United Kingdom: Canadian Television Fund

Day, F., Evey, K. (Producer). (2007). The Guild. Web series retrieved from: http:// watchtheguild.com/

DiMartino, M. D., Konietzko, B., Ehasz, A. (Producer). (2005). Avatar: The Last Airbender [Television series]. Burbank, CA: Nickeledeon

Gordon, L., Levin, L., Wilson, C. et al. (Producer), \& West, S. (2001). Lara Croft: Tomb Raider. United States: Paramount Pictures 
Kapuściński, J., Kabarowski, W., Kowarska, D. (Producer), \& Komasa, J. (Director). (2011). Sala Samobójców. Poland: Studio Filmowe Kadr

Kasanoff, L. Apelian, L., Engelman, R. et al. (Profucer). \& Anderson, P. (Director) (1995). Mortal Kombat. United States: New Line Cinema

Kuchner, D. (Producer), \& Lisberger, S. (Director). (1982). TRON [Motion picture]. United States: Walt Disney Productions

Milton, B. (Producer). (2011), \& Milton, B., Stolt, M. (Director). Min Avatar Og Mig [Motion picture]. Denmar: Det Danske Filminstitut

Okuda, K. (Producer). (1999). Digimon [Television series]. Tokyo Japan: Fuji Television

Silver, J., Wachowski A. \& L. (Producer), \& Wachowski, A. \& L. (Director). (1999). Matrix. United States: Warner Bros. Pictures

Spencer, C. (Producer), \& Moore, R. (Director). (2012). Wreck-it-Ralph [Motion picture]. United States: Walt Disney Studios

Takahashi, N., Ito, T., Watanabe, T., Saito, Y. (Producer), \& Hosoda, M. (Director). (2009). Summer Wars. Japan: Madhouse

Ueda, Y., Abe, S. (Producer). (1998). Serial Experiments Lain [Television series]. Tokyo, Japan: TV Tokyo

\section{Summary}

Due to the growing popularity of video games, gaming itself has become a shared experience among media audiences worldwide. The phenomenon of avatar-based games has led to the emergence of new storytelling practices. The paper proposes a typology of tropes in these avatar-based narratives focusing on non-game case studies. Suggested tropes are also confronted with the latest research on avatars in the area of game studies and current knowledge of the issues concerning the player-avatar relationship. Some of the most popular misconceptions regarding the gameplay experience and its representation in non-game media are exposed as a result of this analysis. The research confirms that popular culture perceives gaming experience as closely related to the player identity, as the latter inspires new genres of non-game narratives.

Keywords: avatars, narrative, storytelling, movies, tv series, light novels

Marta Tymińska is a PhD candidate at the Faculty of Languages at the University of Gdansk, psychology and culture studies graduate, her scholar work focuses on game studies, fan studies and manga studies. 